\title{
Motivos para Adesão e Permanência Discente na Educação Superior a Distância
}

Reasons For Student Adhesion And Permanence In Distance High Education

Motivos Para Adhesión Y Permanencia Discente En La Educación Superior A Distancia
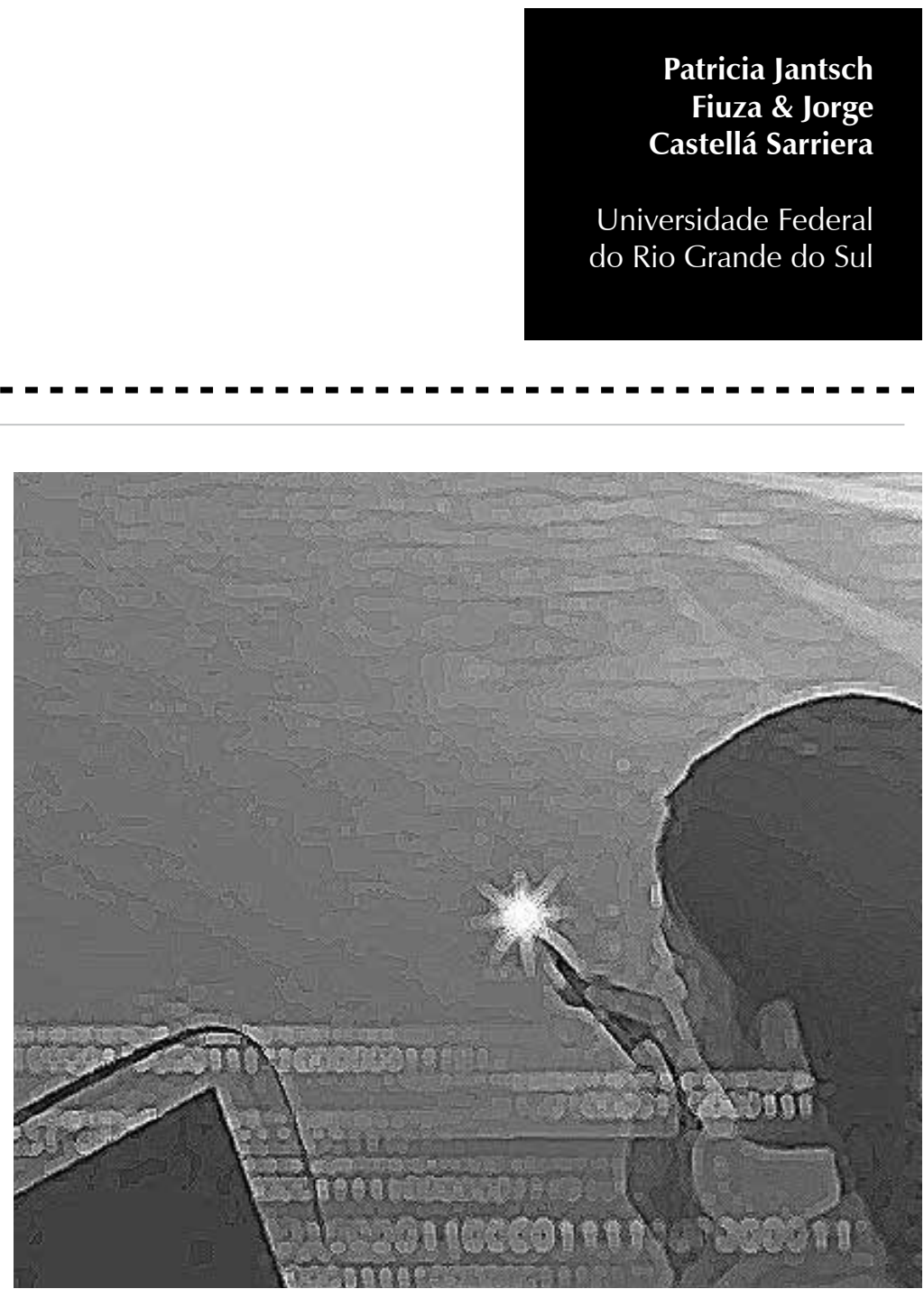
Resumo: Esse artigo apresenta parte de uma pesquisa de doutorado realizada com alunos de cursos superiores a distância de sete IES públicas e privadas do Brasil sobre os motivos da adesão e da permanência nessa modalidade. A partir desses resultados, pretende-se discutir novas estratégias para o fenômeno da evasão. O estudo é exploratório, com abordagem dos dados em uma perspectiva mista, e a coleta utilizou um formulário de pesquisa com as questões disponibilizadas na internet. A amostra constituiu-se de 605 sujeitos, com idades entre 18 a 61 anos $(M=32,39$; $D P=9,25), 216$ homens $(36,0 \%)$ e 384 mulheres (64\%). Os resultados mostram que os fatores de adesão são de origem pessoal, categorizados como identificação pessoal ou afinidade com o curso. Outros fatores importantes no estudo são: flexibilidade, gratuidade, logística, modalidade, acessibilidade e a possibilidade de conciliar outros afazeres com os estudos. Com relação a questões institucionais ou acadêmicas, destaca-se a importância dada ao nome ou ao renome da instituição bem como à qualidade, tanto da IES como do curso e da equipe pedagógica e operacional envolvida. Os resultados permitiram a categorização de 13 itens para os motivos de adesão e de 13 itens para permanência, que, por sua vez, foram organizados em 3 dimensões: questões pessoais ou endógenas ao aluno, questões acadêmicas ou exógenas ao aluno e questões contextuais relacionadas ao que envolve tanto o aluno quanto o curso.

Palavras-chave: Ensino superior. Educação a distância. Estudantes universitários. Motivação.

Abstract: Analysing part of a doctoral research with students from distance education in public and private universities (HEI) in Brazil, this article focuses the reasons of their adherence and permanence in this modality. Based on these results, the article discusses some new strategies for the dropout phenomenom. This is an exploratory study through a data approach with a mixed perspective . The material collected followed a research with questions available on the internet. The sample consisted of 605 persons, aged between 18-61 years $(M=32.39, S D=9.25), 216$ men $(36.0 \%)$ and 384 women $(64 \%)$. The results show that most of the factors are the personnel adhesion categorized as personal identification or course affinity. Other important factors in the study are: flexibility, gratuity, logistics, modality, accessibility and the possibility of combining studies with other activities. Regarding institutional or academic issues, the article highlights the importance given to the "name" or "renown" of the institution and to the quality of the HEI as the course and the educational and operational staff involved. The results allowed the categorization of 13 items for reasons of adherence and 13 items of permanence, which were arranged in three dimensions: personal or endogenous issues in students, academic or exogenous issues of students as well as contextual issues involving the student and the course.

Keywords: High education. Distance education. College students. Motivation.

Resumen: Ese artículo presenta parte de un estudio de doctorado realizado con alumnos de cursos superiores a distancia de siete IES públicas y privadas de Brasil sobre los motivos de la adhesión y de la permanencia en esa modalidad. A partir de esos resultados, se quiere discutir nuevas estrategias para el fenómeno de la evasión. El estudio es exploratorio, con un abordaje de los datos en una perspectiva mixta, y la recolección utilizó un formulario de investigación con las cuestiones puestas a disposición en internet. La muestra se constituyó de 605 sujetos, con edades entre 18 a 61 años $(M=32,39$; DP = 9,25), 216 hombres (36,0\%) y 384 mujeres (64\%). Los resultados muestran que los factores de adhesión son de origen personal, categorizados como identificación personal o afinidad con el curso. Otros factores importantes en el estudio son: flexibilidad, gratuidad, logística, modalidad, accesibilidad y la posibilidad de conciliar otros quehaceres con los estudios. Con relación a cuestiones institucionales o académicas, se destaca la importancia dada al nombre o al renombre de la institución así como a la calidad, tanto de la IES como del curso y del equipo pedagógico y operacional involucrado. Los resultados permitieron la categorización de 13 puntos para los motivos de adhesión y de 13 puntos para permanencia, que, a su vez, fueron organizados en 3 dimensiones: cuestiones personales o endógenas al alumno, cuestiones académicas o exógenas al alumno y cuestiones contextuales relacionadas a lo que involucra tanto el alumno como al curso.

Palabras clave: Educación superior. Educación a distancia. Estudiantes universitarios. Motivación

A educação a distância, $(\mathrm{EaD})$ para o MEC - Ministério da Educação, é a "modalidade educacional na qual a mediação didáticopedagógica nos processos de ensino e aprendizagem ocorre com a utilização de meios e de tecnologias de informação e comunicação, com estudantes e professores desenvolvendo atividades educativas em lugares ou tempos diversos", conforme o Decreto no 5.622, de 19/12/2005, que regulamenta a EaD no Brasil (Brasil, 2005). 
Segundo Silveira e Ribeiro (2005), o termo adesão tem origem no latim adhaesione, e significa, do ponto de vista etimológico, junção, união, aprovação, acordo,

manifestação de solidariedade, apoio; pressupõe relação e vínculo.
A estimativa de crescimento da $\mathrm{EaD}$, segundo o MEC, para o primeiro semestre de 2009, baseada em dados nacionais, foi de $90 \%$ a 100\% no ano, a partir da informação de que havia 760.599 alunos de graduação a distância em 2008 e 145 instituições de ensino superior (IES). (Censo ead.br, 2010). De acordo com o MEC, no ano 2010, $14,6 \%$ das matrículas na graduação foram em cursos a distância, sendo que 80,5\% correspondem ao total de 748.577 em instituições privadas. Segundo os dados, em dez anos, o número de matrículas em EaD cresceu de 5.359, em 2001, para 930.179, em 2010, um crescimento exponencial. A matrícula em cursos presenciais cresceu apenas $80 \%$ nos mesmos dez anos.

Junto a esse crescimento, várias questões vêm sendo levantadas, e entre elas está a evasão na modalidade. Este artigo busca trabalhar essa questão sob outro ponto de vista, o da adesão e da permanência do aluno na EaD. Mas, para trabalhar sob essa perspectiva, é preciso, primeiramente, buscar outras formas de explicar o fenômeno que é utilizando o aluno como ponto de partida da investigação. A partir do aluno e dos motivos que o levam a aderir e a persistir no curso, é possível levantar novas estratégias para discutir a permanência.

Fortalecer os fatores relacionados à permanência pode ser uma das formas de combater a evasão, utilizando os conhecimentos dos quais, até agora, a maioria das instituições não se apropriou, ou seja, o que o aluno pensa, sente e precisa para persistir na modalidade. Este artigo apresenta parte de uma pesquisa de doutorado realizada com alunos de cursos superiores a distância sobre os motivos da sua adesão e permanência nessa modalidade. A partir desses resultados, pretende-se discutir novas estratégias para combater o fenômeno da evasão.

\section{Adesão, permanência, persistência e evasão}

Segundo Silveira e Ribeiro (2005), o termo adesão tem origem no latim adhaesione, e significa, do ponto de vista etimológico, junção, união, aprovação, acordo, manifestação de solidariedade, apoio; pressupõe relação e vínculo. Atualmente, a adesão à EaD tem se evidenciado impulsionada pelo aumento da oferta de cursos nessa modalidade nos últimos anos (Censo ead.br, 2010). Fiuza e Sarriera (2012) sugerem utilizar o termo adesão, com o sentido de adherence, pelo qual o papel do estudante a distância seria ativo, juntamente ao termo permanência, pois somente o termo aderir dá a entender que o sujeito escolheu aquela modalidade de curso, e a permanência englobaria a estada do estudante no curso até sua conclusão, o que alguns autores também chamam de retenção ou de sucesso escolar.

A definição de retenção/permanência é complexa e problemática, por isso um grande número de pesquisas apresenta resultados inconclusivos e muitas vezes contraditórios sobre o assunto (Berge \& Huang, 2004). Os autores optam pelas definições de evasão (attrition), retenção/permanência (retention) e persistência (persistence) da seguinte forma: a) evasão é um declínio no número de estudantes a partir do começo ao fim do curso, programa ou sistema em análise, b) retenção/permanência é a continuada participação dos estudantes em um evento de aprendizagem para conclusão, que, no ensino superior, poderia ser um curso, programa, disciplina ou sistema, e c) persistência é o resultado de decisões dos alunos para continuar participando do evento de aprendizagem em análise. Assim, a definição de retenção ou permanência é mais complicada, pois envolve diferentes medidas adotadas pela própria organização, visto que cada uma adota aspectos 
pertinentes às suas características específicas e ao seu contexto de atuação.

Para Kemp (2001), a persistência na educação a distância também é um fenômeno complexo influenciado por uma multiplicidade de variáveis. Durante a vida, as pessoas encontram uma série de eventos de vida ou estressores, e assumem uma variedade de papéis, um dos quais é o de aluno. Existem variações individuais nas respostas das pessoas ao estresse e às adversidades; alguns indivíduos os enfrentam com sucesso, enquanto outros reagem negativamente. Aqueles que lidam bem com as dificuldades são capazes de superar a sua vulnerabilidade, ou o seu risco, por causa de mecanismos de proteção que operam em momentos decisivos em suas vidas e que os ajudam a ser resilientes. Assim, persistência é um sinônimo para o progresso do aluno que se refere ao comportamento em que os alunos continuam a fazer progressos em um programa ou curso, permanecendo continuamente inscritos, o que equivale à bem-sucedida conclusão do curso (Kemp, 2001). De acordo com Kemp, o único ponto de concordância entre os autores é a natureza multivariada da persistência. As variáveis postuladas incluem aspectos relacionados ao aluno (como plano de fundo ou características predisponentes), às circunstâncias individuais do aluno (por exemplo, mudanças na vida) e ao comprometimento organizacional ou institucional.

Frydenberg (2007) apresenta dados de dois anos de estudo sobre persistência e abandono. A pesquisa demonstrou uma taxa de persistência em cursos on-line de $79 \%$, enquanto os presenciais apresentaram $84 \%$. Os dados para as duas modalidades de curso foram separados por tempo do pedido de retirada: 1) antes de começar, 2) durante a semana inicial e 3) ao longo do curso. Houve uma diferença significativa entre os pedidos nos cursos on-line e presencial para desistências durante a semana inicial. Não houve diferença significativa entre as taxas após o início do curso, o que levou à conclusão de que é improvável que as diferenças nas modalidades sejam um dos principais fatores que influenciam a decisão do aluno de evadir. O estudo também não revelou diferenças de satisfação dos alunos entre as modalidades em relação ao fato de o curso presencial possuir um professor fisicamente próximo, pois parece que a presença de um tutor tenha sido capaz de atenuar a falta de interação olho no olho. Para a autora, as razões dadas para se pedir a retirada de uma classe são bastante semelhantes, porém a grande percentagem de transferência entre os alunos online precisa ser mais bem investigada, principalmente para saber se a transferência é para outro curso online ou para um presencial. Em quarto lugar, o estudo detectou que algo acontece durante a semana de orientação das aulas online, pois a taxa de perda de alunos durante esse período de tempo é o dobro das aulas presenciais, o que levou a algumas considerações sobre a plataforma do curso online, a qualidade ou quantidade de conteúdo, ou sobre se poderia ser uma questão de expectativas do estudante, visto que eram alunos oriundos do ensino presencial (Frydenberg, 2007).

Estudo de Santos e Neto (2009) revelou que os fatores que os alunos evadidos consideraram, ao escolher o curso de graduação em Ciências Biológicas a distância, se deveram ao interesse pela área em 56,76\% das respostas, seguidos por $27,02 \%$ que relataram falta de opção, $27,02 \%$ para melhorar o currículo e $27,02 \%$ por comodidade/flexibilidade da EaD. A gratuidade do curso foi mencionada apenas por $5,41 \%$ dos estudantes da pesquisa. A pesquisa realizada verificou ainda que a maioria dos fatores de evasão é de origem externa ao curso, ou seja, pessoais, como: 
Quando o assunto é a evasão, Fiuza e Sarriera destacam que a literatura não é consistente com relação aos principais fatores. Em seu trabalho, relatam que alguns autores (Abbad, Carvalho, \& Zerbini, 2006; Frydenberg, 2007; Comarella, 2009) enfocam as questões relacionadas às tecnologias e a seu uso como fatores primordiais na desistência de um curso a distância,

enquanto outros destacam fatores pessoais para o abandono

(Favero \& Franco, 2006a; Rossi, 2008; Santos \& Neto, 2009; Comarella, 2009; Almeida, 2010).

E-learning, no estudo de Jun (2005), referese a cursos de curta duração relacionados ao trabalho e realizados no contexto laboral, por isso, esses dados, que devem ser analisados com cuidado, servem para fins de exemplificação de estudos sobre predição de abandono. falta ou má gestão do tempo, priorização de outras atividades, falta de habilidade para EaD, problemas de saúde e não adequação ao modelo, e verificou-se que os fatores internos estão relacionados à falta de acompanhamento do professor-tutor e à falta de apoio/incentivo institucional. O estudo propõe algumas estratégias na dimensão institucional para diminuir as taxas de evasão devido a fatores internos e externos (Santos \& Neto, 2009).

Quando o assunto é a evasão, Fiuza e Sarriera (2012) destacam que a literatura não é consistente com relação aos principais fatores. Em seu trabalho, relatam que alguns autores (Abbad, Carvalho, \& Zerbini, 2006; Frydenberg, 2007; Comarella, 2009) enfocam as questões relacionadas às tecnologias e a seu uso como fatores primordiais na desistência de um curso a distância, enquanto outros destacam fatores pessoais para o abandono (Favero \& Franco, 2006a; Rossi, 2008; Santos \& Neto, 2009; Comarella, 2009; Almeida, 2010). Há também estudos que destacam os fatores de apoio social (Favero \& Franco, 2006; Almeida, 2010), e que culminam com a indicação de se criar serviços de apoio ao aluno (Freitas, 2009; Bardagi \& Hutz, 2009). No entanto, são raros os estudos que conseguem abarcar pelo menos alguns dos multifatores que favorecem o bom desempenho dos alunos de cursos a distância.

Um estudo importante foi o de Jun (2005), que buscava determinar qual o conjunto específico de variáveis que podem melhor prever o abandono de estudantes adultos de cursos e-learning ${ }^{1}$ no local de trabalho. Nessa pesquisa, o autor analisou 23 trabalhos sobre a evasão no período de 1988 a 2001, e classificou os fatores da evasão em cinco categorias: motivação, presente em 18 estudos, questões acadêmicas, em 12 , contexto individual, citado por 06 estudos, integração social, encontrada em 06 trabalhos, e suporte tecnológico, em 04. Em seu estudo de doutorado sobre o tema da evasão em cursos presenciais no Brasil, Cislaghi (2008) sistematizou um panorama geral das principais causas para a evasão no ensino presencial relatadas na literatura, criando um quadro referencial. As causas referidas nos estudos pesquisados foram distribuídas em oito categorias: condições pessoais (familiares, profissionais e financeiras) presente em 14 estudos, didático-pedagógicas e interesses pessoais, ambas presentes em 13 estudos, curso, referida em 10 trabalhos, desempenho acadêmico e ambiente socioacadêmico, ambos em 08 estudos, currículo, encontrado em 06 estudos, e características institucionais, presente em 04 estudos. As categorias foram estabelecidas como resultado de uma análise sistêmica, e, dentro de cada categoria, foram ordenadas pela frequência de estudos que as citam, sugerindo a relevância relativa de cada uma. Ainda segundo o autor, os fatores exógenos para a evasão discente, embora apareçam nos estudos, estão fora do escopo de atuação das instituições de ensino, e, portanto, há muito pouco que elas possam fazer para minimizá-los. Já os fatores endógenos da evasão seriam mais facilmente identificáveis pelas instituições, o que permitiria intervir rapidamente e de modo intenso e contínuo.

Como resultado de seu estudo, Cislaghi e Luz Filho (2009) estabelecem um modelo de permanência discente para IES - Instituições de Ensino Superior brasileiras que apresenta as seguintes categorias: a) desempenho em notas: indicadores de aproveitamento (ex.: notas obtidas em disciplinas e suas respectivas cargas horárias, número de créditos cursados em relação ao total curricular, etc.), b) integração social: fatores que influenciam a habilidade do estudante para desenvolver relacionamentos com colegas e outros estudantes fora dos ambientes acadêmicos rotineiros (ex.: fora das salas de 
aula, fora dos horários de estudo, fora das atividades acadêmicas, etc.), c) integração acadêmica: fatores que influenciam a habilidade do estudante de participar ativamente do ambiente acadêmico na instituição (ex.: relação com docentes dentro e fora da sala de aula, participação em grupos de estudo, horas dedicadas aos estudos, créditos no semestre, etc.), d) compromisso com a instituição: fatores que influenciam a percepção que o estudante tem da instituição na qual está estudando, as suas características principais e o prestígio da instituição (satisfação global com a instituição) e) compromisso com o objetivo: fatores que influenciam a percepção que o estudante tem da qualidade do curso, decorrentes da formação que recebe, e utilidade do diploma correspondente diante do esforço necessário para manter seu vínculo (intenção de concluir o curso, intenção de exercer a profissão), f) condições financeiras: possibilidades de pagamento de despesas com os estudos e subsistência (ex.: taxas, materiais, transporte, estadia) a partir de recursos familiares ou pessoais (ex.: salário, renda, bolsa), g) responsabilidades familiares: necessidade de dispor de tempo e de estrutura para atender as necessidades familiares (dependentes) e h) responsabilidades profissionais: necessidade de dedicação a compromissos profissionais (ex.: carga horária de trabalho, flexibilidade de horário, viagens).

Uma pesquisa qualitativa desenvolvida por Willis e Carmichael (2011) com alunos evadidos de um curso de doutorado presencial indicou cinco problemas principais associados às consequências da evasão: a) disciplina com relacionamento problemático, na qual os desistentes relataram relacionamentos problemáticos com a disciplina de dissertação, em que se sentiram negligenciados, desorientados e até perseguidos, b) carreira como refúgio: todos os desistentes descreveram suas carreiras como um lugar de refúgio a partir do estudo de doutorado; como a frustração com o estudo de doutorado aumentou, cada um começou a refugiarse em sua carreira buscando sentimentos de poder e de pertença, c) emoções experimentadas ao desistir: uma reação emocional negativa era parte da experiência de evadir, e os participantes descreveram como eles ainda valorizavam a obtenção do doutorado no momento da desistência e como experimentaram emoções negativas por terem sido impedidos de obter algo desejado, d) impacto emocional de longo prazo: alguns participantes relataram que as consequências emocionais de desistir foram sentidas por um longo período de tempo; para alguns, as emoções ainda estavam recentes durante as entrevistas da pesquisa, mesmo quando as entrevistas aconteceram dez a vinte e cinco anos após a evasão, e e) impacto emocional sobre os membros da família, ou seja, os participantes não estavam sozinhos em suas reações emocionais ao abandono.

A partir do cenário apresentado sobre a EaD e da necessidade de mais estudos sobre a evasão e a permanência dos alunos nessa modalidade de ensino, principalmente no Brasil, onde ainda são incipientes, buscouse responder à seguinte questão de pesquisa neste estudo: Quais os motivos para adesão e permanência dos estudantes em cursos na modalidade educação a distância no Brasil?

\section{Método}

O estudo desenvolvido é de cunho exploratório, e tem o objetivo de proporcionar maior familiaridade com o problema, com vistas a torná-lo mais explícito, buscando o aprimoramento de ideias e a descoberta de intuições (Gil, 2008). Quanto à metodologia, desenvolveuse um estudo de base com abordagem mista, 
ou seja, parte dos dados coletados foram trabalhados na perspectiva quantitativa, tais como a amostra e suas características, enquanto outros foram analisados na perspectiva qualitativa, na qual o pesquisador pode fazer interpretação ou tirar conclusões sobre seu significado, pessoal e teoricamente, mencionando as lições aprendidas e oferecendo mais perguntas (Creswell, 2007).

Após o primeiro contato telefônico com os responsáveis nas IES, era enviado, via e-mail, o TCLE - Termo de Consentimento Livre e Esclarecido institucional e informações sobre a pesquisa, tais como objetivos, instrumentos e procedimentos éticos. Com o recebimento do aceite da instituição em participar, via assinatura no TCLE institucional, era encaminhado novamente para o responsável um e-mail padrão com informações da pesquisa para os acadêmicos convidando-os a participar. Todos os participantes, instituições e alunos, concordaram em participar, aceitando o TCLE, e foram consideradas todas as questões éticas de pesquisa com seres humanos neste estudo, que foi submetido e aprovado pelo Comitê de Ética em Pesquisa do Instituto de Psicologia da Universidade Federal do Rio Grande do Sul (CEP-PSICO). Os dados sociodemográficos e os motivos para adesão e permanência foram coletados através de um formulário de pesquisa com as questões do instrumento disponibilizadas em um site na internet.

\section{Participantes}

A amostra deste estudo foi constituída por 605 sujeitos, com idades entre 18 a 61 anos ( $M$ $=32,39 ; \mathrm{DP}=9,25), 216$ homens $(36,0 \%)$ e 384 mulheres $(64 \%)$, estudantes de cursos de graduação e pós-graduação de sete instituições públicas e privadas de ensino superior do Brasil, que ofertam cursos na modalidade a distância.

Tabela 1. Frequências e percentuais da amostra por IES

\begin{tabular}{llll}
\hline IES & Frequency & Valid percent & Cumulative percent \\
\hline UFSC & 341 & 56,4 & 56,4 \\
UFRGS & 16 & 2,7 & 59,1 \\
UFPR & 75 & 12,4 & 71,5 \\
UNB & 15 & 2,5 & 74,0 \\
UNIASSELVI & 74 & 12,2 & 86,2 \\
ULBRA & 11 & 1,8 & 88,0 \\
UNIVALI & 52 & 8,6 & 96,6 \\
Outros & 11 & 1,8 & 98,4 \\
Não respondeu & 5 &, 8 & 99,2 \\
Missing & 5 &, 8 & 100,0 \\
Total & 605 & 100,0 & 100,0 \\
\hline
\end{tabular}

Nota. Elaborada pelos autores

Entre as instituições públicas, destacam-se a Universidade Federal de Santa Catarina - UFSC com 341 (56,4\%) participantes, a Universidade Federal do Paraná - UFPR, com 75 (12,4\%), a Universidade Federal do Rio Grande do Sul - UFRGS, com 16 (2,7\%), e a Universidade de Brasília - UNB, com 15 (2,5\%). As instituições privadas que participaram são o Centro Universitário Leonardo da Vinci - UNIASSELVI, com 74 (12,2\%) participantes, a Universidade do Vale do Itajaí - UNIVALI, com 52 (8,6\%), e a Universidade Luterana do Brasil - ULBRA, com 11 (1,8\%). 
Vale destacar que, dos 605 sujeitos da amostra, 516 são trabalhadores, ou seja, precisam conciliar estudos e trabalho, e, além disso, têm-se um total de 398 sujeitos entre casados, separados, divorciados e viúvos, sendo que 263 declararam morar com filhos ou companheiros e filhos, como pode ser visto na Tabela 2.

Tabela 2. Frequências e percentuais da amostra por gênero, escolaridade, estado civil, situação laboral e situação familiar

\begin{tabular}{|c|c|c|c|}
\hline & & $\mathrm{N}$ de respostas & $\%$ \\
\hline \multirow{2}{*}{ Gênero } & Masculino & 216 & 36,0 \\
\hline & Feminino & 384 & 64,0 \\
\hline \multirow[t]{8}{*}{ Escolaridade } & Ensino médio & 18 & 3,0 \\
\hline & Cursando graduação & 354 & 59,0 \\
\hline & Graduado & 87 & 14,5 \\
\hline & Cursando pós-graduação & 47 & 7,8 \\
\hline & Especialização & 81 & 13,5 \\
\hline & Mestrado & 9 & 1,5 \\
\hline & Doutorado & 1 & 0,2 \\
\hline & Outros & 3 & 0,5 \\
\hline \multirow[t]{5}{*}{ Estado civil } & Solteiro & 201 & 33,5 \\
\hline & Casado & 364 & 60,7 \\
\hline & Separado/divorciado & 33 & 5,5 \\
\hline & Viúvo & 1 & 0,2 \\
\hline & Outros & 1 & 0,2 \\
\hline \multirow[t]{3}{*}{ Situação laboral } & Trabalha & 516 & 86,0 \\
\hline & Não trabalha & 71 & 11,8 \\
\hline & Não respondeu & 13 & 2,2 \\
\hline \multirow[t]{8}{*}{ Situação familiar } & Sozinho & 49 & 8,2 \\
\hline & Com companheiro e sem filhos & 133 & 22,2 \\
\hline & Com companheiro e com filhos & 230 & 38,3 \\
\hline & Pais ou parentes & 133 & 22,2 \\
\hline & Filhos & 33 & 5,5 \\
\hline & Amigos ou conhecidos & 6 & 1,0 \\
\hline & Outros & 6 & 1,0 \\
\hline & Não respondeu & 10 & 1,7 \\
\hline
\end{tabular}

Nota. Elaborada pelos autores

\section{Instrumento}

Foi elaborado um instrumento online com perguntas fechadas com alternativa de resposta múltipla, previamente categorizadas no estudo-piloto da pesquisa de doutorado, sobre os dados sociodemográficos e de cunho pessoal, tais como idade, sexo, estado civil, escolaridade, situação familiar, situação laboral, desempenho acadêmico no curso a distância e as principais dificuldades ou problemas encontrados para a permanência no curso, e questões abertas sobre os motivos para escolha do curso a distância e atividades/práticas do professor que incentivaram a permanência. 


\section{Análise de dados}

As respostas às questões fechadas foram trabalhadas com o software SPSS - Statistical Package for the Social Sciences 17.0, e as questões abertas foram categorizadas com a ajuda do software Atlas TI 6.0 para posterior análise de conteúdo, a partir da perspectiva teórica de Bardin (2004). As etapas para realização da análise foram: retorno aos objetivos de pesquisa, análise prévia (organização do material, operacionalização e sistematização), contato inicial com a mensagem, análise textual e temática, caracterizando a estrutura e os conceitos mais utilizados, análise propriamente dita (codificação, categorização e quantificação), e, finalmente, o tratamento dos resultados obtidos e a interpretação das informações.

A análise qualitativa foi utilizada em duas perguntas do questionário. A primeira questão, que pedia para destacar "os motivos da escolha deste curso", foi respondida por 583 participantes; a segunda questão aberta perguntava "quais atividades, comportamentos, práticas do professor contribuíram para sua permanência no curso", e foi respondida por 267 pessoas.

\section{Resultados e discussão}

A questão sobre o desempenho do aluno no curso era de múltipla escolha, sendo que as alternativas de respostas variavam desde muito acima da média, acima da média, dentro da média, abaixo da média até muito abaixo da média. Foi uma questão direcionada aos próprios alunos, sendo, portanto, um resultado do seu autorrelato. As respostas a essa questão apresentaram uma distribuição bastante peculiar, formando dois polos distintos, um com os alunos que se definem como acima da média e muito acima da média, totalizando 180 sujeitos, e outro extremo com aqueles que se avaliam abaixo da média ou muito abaixo da média com 402 casos; somam-se a esses 8 alunos que se autorrelataram na média e 15 que não responderam a essa questão. Esses resultados chamam a atenção, visto que se esperava uma distribuição normal para essas respostas. Assim, pode-se pensar que esses alunos ou possuem uma baixa autoestima e não acreditam no seu potencial, e talvez também não acreditem na qualidade do curso que frequentam, ou então, por estarem em uma modalidade diferente, visto que a maioria vem da educação presencial tradicional, podem cobrar-se mais em relação ao desempenho no curso, ou seja, essa seria uma questão relacionada às expectativas dos estudantes, como revelou o estudo de Frydenberg (2007).

De acordo com Nassar et al. (2008), as dificuldades pessoais para um bom desempenho e aproveitamento nas disciplinas que podem resultar em reprovações e a demora excessiva para a integralização curricular, a redução das perspectivas de colocação e a valorização profissional pelo mercado de trabalho, a mudança de interesses ou de prioridades pessoais e a necessidade de transferência familiar para outro Município ou Estado, entre outros, estão entre as causas da evasão. Nesse sentido, o grupo da amostra parece necessitar de uma atenção especial com relação ao desempenho, fator também destacado por Cislaghi (2008) como risco à permanência dos estudantes nos cursos.

Em relação à primeira questão aberta sobre "os motivos da escolha deste curso", 583 estudantes a responderam. Essa questão teve como objetivo identificar os motivos da escolha pelo curso a distância, pelo relato do próprio estudante. Essas respostas foram tratadas por meio de análise de conteúdo. Após organização do material coletado e da realização da leitura flutuante, foram definidas as categorias que caracterizavam os motivos mencionados, e nelas foram 
enquadrados termos semelhantes, bem como a incidência, como mostra a Tabela 3.

Tabela 3. Categorias, termos associados e incidência para os motivos da escolha pelo curso a distância

\begin{tabular}{|c|c|c|c|}
\hline Categoria & Principais termos associados & $\begin{array}{l}\text { Número de respostas } \\
\text { na categoria }\end{array}$ & $\%$ \\
\hline $\begin{array}{l}\text { Identificação } \\
\text { pessoal/afinidade } \\
\text { com o curso } \\
\text { Flexibilidade }\end{array}$ & $\begin{array}{l}\text { Gosto da área; interesse pessoal } \\
\text { pelo curso; me identifico com; } \\
\text { afinidade; adoro; amo. } \\
\text { Flexibilidade; horários flexíveis; } \\
\text { tempo maleável; administração do } \\
\text { tempo; adequação de horários; } \\
\text { horários disponíveis; hora que } \\
\text { quiser; liberdade de horários; } \\
\text { facilidade de horário; flexibilidade } \\
\text { de local. }\end{array}$ & 100 & 12,60 \\
\hline Gratuidade & $\begin{array}{l}\text { Por ser gratuito; gratuidade; } \\
\text { universidade gratuita; ensino } \\
\text { gratuito; estudar de graça; não } \\
\text { haver mensalidade; não precisa } \\
\text { pagar; não tinha como pagar; falta } \\
\text { de recurso. }\end{array}$ & 88 & 11,55 \\
\hline $\begin{array}{l}\text { Renome/ } \\
\text { credibilidade IES }\end{array}$ & $\begin{array}{l}\text { Pela instituição; instituição de } \\
\text { renome; reconhecimento da } \\
\text { universidade; por ser federal; } \\
\text { universidade pública; grande } \\
\text { universidade; } \\
\text { conceituada; universidade } \\
\text { instituição de alto nível; } \\
\text { universidade de excelente gabarito; } \\
\text { nome da instituição; reputação da } \\
\text { instituição. }\end{array}$ & 79 & 10,37 \\
\hline Logística & $\begin{array}{l}\text { Proximidade; perto de casa; } \\
\text { próximo; sem deslocamento; sem } \\
\text { sair da cidade; sem sair de casa; } \\
\text { na localidade; acesso ao polo; } \\
\text { impossibilidade de frequentar } \\
\text { diariamente; flexibilidade detempo } \\
\text { e local; versatilidade de tempo; } \\
\text { menos tempo com deslocamento; } \\
\text { encontros programados. }\end{array}$ & 76 & 9,97 \\
\hline Modalidade EaD & $\begin{array}{l}\text { Por ser a distância; é a distância; } \\
\text { ser EaD; ofertado a distância; } \\
\text { modalidade; ser não presencial; por } \\
\text { não ser presencial; semipresencial; } \\
\text { não ter aulas presenciais; falta de }\end{array}$ & 68 & 8,92 \\
\hline
\end{tabular}


continuação da tabela 3

\begin{tabular}{|c|c|c|c|}
\hline Categoria & Principais termos associados & $\begin{array}{l}\text { Número de respostas } \\
\text { na categoria }\end{array}$ & $\%$ \\
\hline & $\begin{array}{l}\text { tempo para o presencial; única } \\
\text { opção/oportunidade; inovação na } \\
\text { modalidade. }\end{array}$ & 67 & 8,79 \\
\hline $\begin{array}{l}\text { Área de atuação } \\
\text { / identificação } \\
\text { profissional }\end{array}$ & $\begin{array}{l}\text { Área que atuo; já atuo na área; área } \\
\text { de trabalho; relação com minha } \\
\text { área de atuação; compatibilidade } \\
\text { com área de atuação; ligado com } \\
\text { área de atuação; adequado à área } \\
\text { de atuação profissional; afinidade } \\
\text { com área de atuação; já trabalho e } \\
\text { não tenho formação; necessidade } \\
\text { de um diploma na área; interesse } \\
\text { na área (atual e futuro); interesse } \\
\text { profissional. }\end{array}$ & & \\
\hline $\begin{array}{l}\text { Conhecimento / } \\
\text { aprimoramento }\end{array}$ & $\begin{array}{l}\text { Conhecimento; adquirir } \\
\text { conhecimentos; aumentar } \\
\text { conhecimentos; ampliar } \\
\text { conhecimentos; aperfeiçoar } \\
\text { conhecimento; aprimorar } \\
\text { conhecimento; atualização; } \\
\text { mais conhecimento; reciclagem; } \\
\text { aprofundamento; agregar } \\
\text { conhecimentos; abrangência de } \\
\text { conhecimentos; complementar } \\
\text { conhecimento; aprimoramento } \\
\text { (pessoal e profissional); } \\
\text { aprendizado. }\end{array}$ & 61 & 8,01 \\
\hline $\begin{array}{l}\text { Qualidade (IES/ } \\
\text { curso/equipe) }\end{array}$ & $\begin{array}{l}\text { Qualidade; ser de qualidade; } \\
\text { qualidade reconhecida da IES; } \\
\text { instituição de qualidade; qualidade } \\
\text { da universidade; faculdade de } \\
\text { qualidade; qualidade do ensino; } \\
\text { ensino de qualidade; qualidade } \\
\text { do curso; qualidade do material; } \\
\text { qualidade do conteúdo; nome da } \\
\text { faculdade proporciona qualidade; } \\
\text { bom destaque ao ensino. }\end{array}$ & 39 & 5,12 \\
\hline Oportunidade & $\begin{array}{l}\text { Oportunidade; oportunidade de } \\
\text { estudar de graça; oportunidade de } \\
\text { fazer faculdade; oportunidade de } \\
\text { voltar aos estudos; oportunidade } \\
\text { de fazer outra faculdade; primeira }\end{array}$ & 38 & 4,99 \\
\hline
\end{tabular}


continuação da tabela 3

\begin{tabular}{|c|c|c|c|}
\hline Categoria & Principais termos associados & $\begin{array}{l}\text { Número de respostas } \\
\text { na categoria }\end{array}$ & $\%$ \\
\hline & $\begin{array}{l}\text { oportunidade que apareceu; } \\
\text { oportunidade de estudar numa } \\
\text { federal; oportunidade que surgiu; } \\
\text { única oportunidade. }\end{array}$ & & \\
\hline Conciliar & $\begin{array}{l}\text { Conciliar trabalho; conciliar } \\
\text { estudos e trabalho; conciliar } \\
\text { estudos e família; conciliar } \\
\text { trabalho, estudo e família; } \\
\text { conciliar trabalho, família e } \\
\text { lazer; conciliar vida pessoal e } \\
\text { profissional; administração vida } \\
\text { pessoal e profissional; mudanças } \\
\text { frequentes. }\end{array}$ & 24 & 3,15 \\
\hline Valor & $\begin{array}{l}\text { Preço; valor reduzido; } \\
\text { mensalidade mais barata; menos } \\
\text { custos; custo benefício; motivos } \\
\text { financeiros; motivos de ordem } \\
\text { econômica; custo; possível de } \\
\text { pagar. }\end{array}$ & 15 & 1,97 \\
\hline Acessibilidade & $\begin{array}{l}\text { Acessibilidade; acesso; facilidade } \\
\text { de acesso. }\end{array}$ & 11 & 1,44 \\
\hline TOTAL & & 762 & 100 \\
\hline
\end{tabular}

Nota. Elaborada pelos autores

A incidência das categorias também é apresentada na Tabela 3, e vale destacar que, dos 583 respondentes, foram considerados os motivos isoladamente, que totalizaram 762 respostas, isso porque muitas vezes foi relacionado mais de um motivo para escolha do curso.

No caso do presente estudo, a identificação pessoal ou a afinidade pelo curso é que foi o principal fator destacado, com 13,12\%. Jun (2005) também definiu uma categoria chamada contexto individual. Nessa categoria, foram encontradas observações dos estudantes como as seguintes: "Afinidade com o curso, gosto de estudar..." e "por gostar do conhecimento e por querer ser professor".

Em seguida, vem a flexibilidade, com $12,60 \%$, item no qual aparece, talvez, a principal característica da EaD, a possibilidade de estudar a qualquer tempo e lugar. Esse foi o segundo principal fator para a escolha dos cursos.

Em terceiro lugar, apareceu a gratuidade, com 11,55\%. Vale destacar que os participantes desta pesquisa não eram evadidos, e sim, alunos matriculados e frequentes em seus cursos a distância. Se for considerado que $74,5 \%$ dos respondentes eram alunos de cursos em 
universidades federais e que entre esses alunos houve $14,67 \%$ de respostas sobre a gratuidade, chega-se quase ao triplo do encontrado no estudo de Santos e Neto, no qual todos participantes eram de um curso em uma universidade pública. Os 25,5\% de estudantes de cursos privados são responsáveis pelos $1,97 \%$ de respostas sobre o valor do curso. Somando as respostas à gratuidade (88) com as respostas sobre valor (15), temos um total de 103 respostas relativas a questões financeiras, o que dá um percentual de $13,52 \%$. No estudo de Cislaghi (2008), a categoria condições pessoais engloba dificuldades financeiras e dificuldade de conciliar atividades familiares e profissionais com o estudo.

Outro fator destacado para adesão ao curso foi o renome e a credibilidade da IES, com 79 ocorrências, que correspondem ao percentual de 10,37\%. Considerando que a modalidade de $\mathrm{EaD}$ ainda sofre preconceitos, esse quesito é muito avaliado pelos alunos, pois pressupõe-se que a instituição mantenha a qualidade de seus cursos presenciais quando oferta a modalidade a distância.

A logística foi citada 76 vezes (9,97\%), e corresponde a questões relacionadas a não necessidade de deslocamento, proximidade com o polo de apoio presencial e economia de tempo e dinheiro como pode ser visto nos seguintes relatos: "Posso fazer os meus horários de estudo sem precisar sair de casa regularmente" e "Ainda posso considerar o fato de ter uma vida profissional bastante atípica, com bastantes viagens, o que impossibilitaria a presença nas aulas se elas fossem todas as noites".

O fato de o curso ser na modalidade EaD apareceu em sexto lugar, com 68 citações $(8,92 \%)$, o que mostra que vários alunos optaram pela modalidade em função das suas características específicas. Em seguida, vem a categoria área de atuação ou identificação profissional, com 67 menções $(8,79 \%)$, na qual se percebe que a escolha se deu em função de a pessoa já estar no mercado de trabalho e necessitar de formação, atualização e, em alguns casos, do próprio diploma.

A categoria conhecimento e aprimoramento engloba aqueles que informaram que estudam, pois querem obter mais conhecimentos ou aprimorá-los, e teve 61 ocorrências que correspondem a 8,01\%, como: "Vi no curso a possibilidade de aprimorar meus conhecimentos em outra área".

A qualidade da IES, curso e/ou equipe também merece destaque, com 39 menções, o que corresponde a 5,12\%, seguida pela questão oportunidade, que foi citada 38 vezes (4,99\%). Algumas respostas merecem ser destacadas: "Oportunidade de estudar de graça, em uma universidade pública" e "Sempre gostei de matemática, e, por ser oferecido gratuitamente pela Universidade Federal, não poderia perder esta oportunidade".

Com menos destaque, aparecem "conciliar", com 24 citações (3,15\%), "valor", com 15 ocorrências (1,97\%), e "acessibilidade", com $11(1,44 \%)$.

A segunda questão aberta investigava "quais atividades, comportamentos, práticas do professor contribuíram para sua permanência no curso", e foi respondida por 267 estudantes. Essa questão teve como objetivo identificar as atividades, comportamentos e práticas do professor que, segundo a visão dos estudantes, os ajudaram a permanecer no curso. Novamente, após a categorização das respostas, utilizou-se a análise de conteúdo. A seguir, apresentase a Tabela 4, com as categorias, os termos associados e a incidência das categorias. Dos 
267 respondentes, totalizou-se uma contagem de 431 fatores, pois novamente foi relacionado, por alguns participantes, mais de um fator para a permanência no curso.

Tabela 4. Categorias, termos associados e incidência das atividades que contribuíram para a permanência

\begin{tabular}{|c|c|c|c|}
\hline Categoria & Principais termos associados & $\begin{array}{l}\text { Número de respostas } \\
\text { na categoria }\end{array}$ & $\%$ \\
\hline $\begin{array}{l}\text { Atitude/ } \\
\text { comportamento do } \\
\text { professor }\end{array}$ & $\begin{array}{l}\text { Ajuda; atenção; incentivos; } \\
\text { dinamismo; comprometidos; } \\
\text { boa comunicação; professores } \\
\text { doutores; professores competentes; } \\
\text { interessados; empenho; } \\
\text { dedicação; disponibilidade. }\end{array}$ & 78 & 18,10 \\
\hline Atividades & $\begin{array}{l}\text { Atividades práticas; atividades } \\
\text { online (chat, fóruns, skype, } \\
\text { e-mails); atividades em grupo; } \\
\text { atividades de motivação; atividades } \\
\text { complementares; atividades a } \\
\text { distância; atividades desafiadoras; } \\
\text { seminários integradores; seminários } \\
\text { interdisciplinares; pesquisa; estudo } \\
\text { de campo; trabalhos; exercícios; } \\
\text { estágio. }\end{array}$ & 72 & 16,70 \\
\hline Motivação / incentivos & $\begin{array}{l}\text { Motivação; incentivos; } \\
\text { vontade; estímulos positivos; } \\
\text { encorajamento; }\end{array}$ & 56 & 13,00 \\
\hline $\begin{array}{l}\text { Atitude / } \\
\text { comportamento do } \\
\text { tutor }\end{array}$ & $\begin{array}{l}\text { Auxílio; atuação; suporte; } \\
\text { lembretes; orientações; incentivos; } \\
\text { contato; disposição; retorno } \\
\text { (feedback); socialização. }\end{array}$ & 49 & 11,37 \\
\hline $\begin{array}{l}\text { Material didático / } \\
\text { conteúdo }\end{array}$ & $\begin{array}{l}\text { Material didático; conteúdo; } \\
\text { materiais; material impresso; livro; } \\
\text { vídeoaulas; }\end{array}$ & 27 & 6,26 \\
\hline $\begin{array}{l}\text { Questões afetivas / } \\
\text { sentimentais }\end{array}$ & $\begin{array}{l}\text { Carinho; coleguismo; } \\
\text { reciprocidade; atenção; } \\
\text { compreensão; confiança; } \\
\text { afetividade; dedicação; } \\
\text { autonomia. }\end{array}$ & 25 & 5,80 \\
\hline Aulas & $\begin{array}{l}\text { Aulas; aulas a distância; aulas } \\
\text { virtuais; aulas presenciais; aulas } \\
\text { práticas; } \\
\text { Videoconferência; videoaulas; }\end{array}$ & 24 & 5,57 \\
\hline
\end{tabular}


continuação da tabela 4

\begin{tabular}{|c|c|c|c|}
\hline Categoria & Principais termos associados & $\begin{array}{l}\text { Vúmero de respostas } \\
\text { na categoria }\end{array}$ & $\%$ \\
\hline $\begin{array}{l}\text { Recursos } \\
\text { tecnológicos }\end{array}$ & $\begin{array}{l}\text { vídeos; ambiente; ambiente de } \\
\text { aprendizagem; recursos. } \\
\text { Interação; trocas; integração; }\end{array}$ & 24 & 5,57 \\
\hline $\begin{array}{l}\text { Interação / } \\
\text { comunicação }\end{array}$ & $\begin{array}{l}\text { interatividade; comunicação } \\
\text { Persistência; vontade; força de }\end{array}$ & 23 & 5,34 \\
\hline Persistência & $\begin{array}{l}\text { vontade; nunca desistir; empenho; } \\
\text { determinação. }\end{array}$ & 16 & 3,71 \\
\hline Disciplinas & $\begin{array}{l}\text { Disciplina; introdução à educação a } \\
\text { distância; primeira disciplina; prática } \\
\text { docente. }\end{array}$ & 16 & 3,71 \\
\hline $\begin{array}{l}\text { Desempenho } \\
\text { pessoal }\end{array}$ & $\begin{array}{l}\text { Desempenho nas disciplinas; } \\
\text { estudo autodidata; ser vencedor; } \\
\text { compreensão dos conteúdos. }\end{array}$ & 11 & 2,55 \\
\hline $\begin{array}{l}\text { Flexibilidade de } \\
\text { horários }\end{array}$ & $\begin{array}{l}\text { Flexibilidade de horários; autonomia } \\
\text { de horários; administração de horários; } \\
\text { disponibilidade de horários. }\end{array}$ & 10 & 2,32 \\
\hline TOTAL & & 431 & 100 \\
\hline
\end{tabular}

Nota. Elaborada pelos autores

As informações coletadas resultaram em 13 categorias, que foram didaticamente agrupadas em três dimensões principais: questões pessoais, também chamadas de endógenas ao aluno, questões acadêmicas ou exógenas ao aluno e questões contextuais relacionadas ao que envolve tanto o aluno quanto o curso. A Figura 1 ilustra esse modelo sintético de práticas que podem ser adotadas para incentivar a permanência dos alunos, nas três dimensões categorizadas a posteriori. 


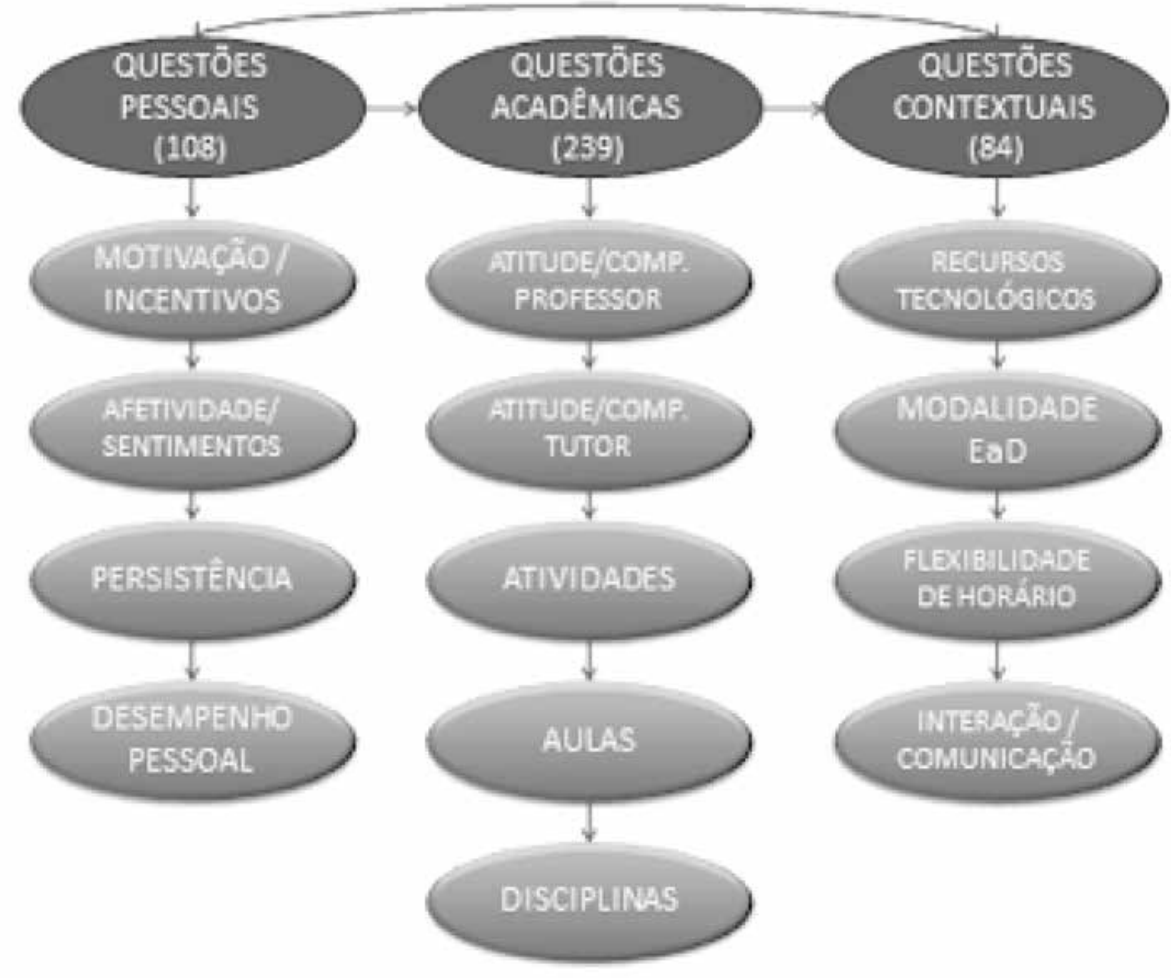

Figura 1. Dimensionamento das categorias relativas à permanência Nota. Elaborada pelos autores

Alguns autores apresentam modelos sintéticos da evasão. Xenos, Pierrakeas, e Pintelas (2002) apresentam três categorias principais: a) fatores internos do aluno, b) fatores relativos ao curso e c) fatores sociodemográficos. Já o modelo de Rovai (como citado em Santos \& Neto, 2009) destaca: a) características dos estudantes, b) habilidades, c) fatores internos (relacionados ao curso) e d) fatores externos (incluem família e trabalho). Kemp (2001) também apresenta um modelo que abarca a natureza multivariada da persistência, que inclui: a) aspectos relacionados ao aluno, b) às circunstâncias individuais do aluno e c) comprometimento organizacional ou institucional.

As categorizações e as análises realizadas neste estudo são um passo inicial na tentativa de estabelecer indicadores para um modelo de permanência discente na EaD, ao contrário dos estudos já citados acerca da evasão. O modelo criado por Cislaghi (2008) abre caminho, mas não abarca as características específicas da $\mathrm{EaD}$, tampouco se preocupa com as questões pessoais que são o foco deste trabalho.

\section{Considerações finais}

Este estudo buscou identificar os motivos para a escolha e a permanência em cursos de graduação na modalidade a distância; entendendo os motivos dos estudantes, procurou compreender a complexidade que envolve a questão da adesão e da permanência na modalidade e identificar quais fatores pessoais, institucionais e contextuais afetam o sucesso ou não do aluno em um curso superior a distância. 
A análise das respostas da amostra pesquisada mostrou que a maioria dos fatores para a escolha do curso, neste artigo, denominada adesão, é de origem pessoal, e foi categorizada como identificação pessoal ou afinidade com o curso. Outros fatores que também se mostraram importantes no estudo são a flexibilidade, característica importante da modalidade, seguida pela gratuidade. Esta última se destacou, pois a amostra acabou sendo composta por $74,5 \%$ de alunos oriundos de cursos de instituições de ensino superior federais, que, a partir da criação da UAB - Universidade Aberta do Brasil, pelo Decreto no 5.800, de 2006, tem oferecido vagas na modalidade a distância em todo o Brasil.

Outras respostas que também se destacaram e dizem respeito à modalidade são a logística do curso, a própria modalidade, a acessibilidade e a possibilidade de conciliar outros afazeres com os estudos. Com relação a questões institucionais ou acadêmicas, merecem destaque a importância dada ao nome ou ao renome da instituição bem como à qualidade, tanto da IES como do curso e da equipe pedagógica e operacional envolvida.

Existem algumas limitações para este estudo. Suas conclusões representam as experiências de um pequeno número de estudantes da $\mathrm{EaD}$, se considerarmos o número de matrículas existentes na modalidade no Brasil, que, segundo o Censo Ead.br (2010), foi de 1.075.272 em todos os níveis de ensino, inclusive cursos de extensão e capacitação, que, confrontados com os dados do INEP de cursos oficiais (graduação, tecnológicos e pós-graduação), chegaram a 856.000 matrículas em 2009. Além disso, outras características da amostra, tais como o fato de a maioria dos participantes ser oriunda de instituições públicas, também não condiz com o cenário real, que, conforme censo educacional do MEC, de 2007, aponta o percentual de cerca de $25 \%$ na educação pública a distância (Censo Ead.br, 2010). Esse cenário não permite generalizar os achados para a realidade brasileira.

No entanto, com relação à permanência, foi possível, a partir deste estudo, criar um modelo sintético composto por três dimensões principais, que envolvem as questões pessoais, ou endógenas ao aluno, as questões acadêmicas ou exógenas ao aluno e as questões contextuais, relacionadas ao que envolve tanto o aluno quanto o curso. Assim, o objetivo de explorar as questões relacionadas pelos alunos para a sua permanência no curso, sua categorização e sistematização foi alcançado.

Patricia Jantsch Fiuza

Doutora pós-doutora em Psicologia pela Universidade Federal do Rio Grande do Sul. Docente da Universidade Federal de Santa Catarina, Araranguá - SC - Brasil.

E-mail: pjfiuza@yahoo.com.br

\section{Jorge Castellá Sarriera}

Pós-doutor em Psicologia pela Universidade de Barcelona e pela University of San Francisco. Docente do Programa de Pós-graduação em Psicologia da Universidade Federal do Rio Grande do Sul, Porto Alegre - RS - Brasil. E-mail: sarriera@terra.com.br

Endereço para envio de correspondência:

Instituto de Psicologia da UFRGS, sala 122. Rua Ramiro Barcelos, 2006, Santa Cecília. CEP: 90035-003.Porto Alegre, RS 


\section{Referências}

Abbad, G., Carvalho, R. S. \& Zerbini, T. (2006, jul./dez.). Evasão em curso via internet: explorando variáveis explicativas. RAE-eletrônica, 5(2), 00-00. doi: http://dx.doi.org/10.1590/ S1676-56482006000200008

Almeida, O. C. S. (2010, setembro). Investigando os fatores influenciadores da desistência de cursos a distância. In Associação Brasileira de Educação a Distância. Trabalhos científicos, $16^{\circ}$ Congresso Internacional ABED de Educação a Distância. Foz do Iguaçu, Brasil: ABED. Recuperado em 02 out., 2011, de http://www.abed.org.br/congresso2010/ $\mathrm{cd} / 252010162044$.pdf.

Bardagi, M. P., \& Hutz, C. S. (2009). Não havia outra saída: percepções de alunos evadidos sobre o abandono do curso superior. Psico- USF, 14, 95-105. . doi: http://dx.doi. org/10.1590/S1413-82712009000100010

Bardin, L. (2004). Análise de conteúdo. Lisboa: Edições 70.

Berge, Z., \& Huang, Y. (2004, maio). A model for sustainable student retention: A holistic perspective on the student dropout problem with special attention to e-learning. DEOSNEWS, 13(5), 1-26. Recuperado em 15 setembro, 2011, de: http://www.ed.psu.edu/acsde/deos/deosnews/ deosnews13 5.pdf

Brasil. (2005). Decreto $n^{\circ} 5.622$, de 19 de dezembro de 2005. Regulamenta o Art. 80 da Lei no 9.394, de 20 de dezembro de 1996, que estabelece as diretrizes e bases da educação nacional. Recuperado em 20 jan., 2007, de http:// www.planalto.gov.br/ccivil/_Ato2004-2006/2005/Decreto/ D5622.htm

Brasil. (2006). Decreto $n^{\circ}$ 5.800, de 08 de junho de 2006. Dispõe sobre o Sistema Universidade Aberta do Brasil - UAB. Recuperado em 15 jun., 2012, de http://www.planalto.gov. br/ccivil_03/_ato2004-2006/2006/decreto/d5800.htm

Censo ead.br. (2010). Associação Brasileira de Educação a Distância . São Paulo: Pearson Education do Brasil.

Cislaghi, R. (2008). Um modelo de sistema de gestão do conhecimento em um framework para a promoção da permanência discente no ensino de graduação. (Dissertação Mestrado). Programa de Pós-Graduação em Engenharia e Gestão do Conhecimento. Universidade Federal de Santa Catarina, Florianópolis, SC.

Cislaghi, R., \& Luz Filho, S. S. (2009). Um framework para a promoção da permanência discente no ensino de graduação e um modelo de sistema de gestão do conhecimento para ies brasileiras. In IX Colóquio Internacional sobre Gestão Universitária na América do Sul, Florianópolis, SC.

Comarella, R. L. (2009). Educação superior a distância: evasão discente. (Dissertação de Mestrado). Universidade Federal de Santa Catarina, Centro Tecnológico. Programa de PósGraduação em Engenharia e Gestão do Conhecimento. Florianópolis, SC.

Creswell, J. W. (2007). Projeto de pesquisa: métodos qualitativo, quantitativo e misto (2a. ed.). Porto Alegre: Artmed.

Fávero, R. V. M., \& Franco, S. R. K. (2006a, novembro). Um estudo sobre a permanência e a evasão na educação a distância. Sociedade Brasileira de Informática na Educação. Workshop Informática e Aprendizagem em Organizações. Brasília, DF: SBIE. Recuperado em 05 nov., 2008, de http:// www.ucb.br/prg/professores/germana/sbie2006-ws/artigos/ favero-franco.pdf

Fávero, R. V. M., \& Franco, S. R. K. (2006, dezembro). Um estudo sobre a permanência e a evasão na educação a distância. Renote, 4(2), 1-10. Recuperado em 05 nov., 2008, de http://www.cinted.ufrgs.br/renote/dez2006/ artigosrenote/25103.pdf.
Fiuza, P. J. \& Sarriera, J. C. (2012). Refletindo sobre evasão, adesão e permanência em cursos na modalidade de educação a distância. In E. Netto Zanette, G. F. Giacomazzo \& P. Jantsch Fiuza (Orgs.), Tecnologias e inovações nas práticas pedagógicas: trajetórias e experiências (pp. 149173). Jundiaí, SP: Paco Editorial.

Freitas, K. S. (2009, jan./jun.). Alguns estudos sobre evasão e persistência de estudantes. EccoS, 2(1), 247-264. Recuperado em 09 out., 2010, de http://www.uninove.br/ PDFs/Publicacoes/eccos/eccos_v11n1/eccosv11n1_3i1062. pdf

Frydenberg, J. (2007). Persistence in university continuing education online classes. The International Review of Research In Open And Distance Learning, 8(3), 1-15. Article 8.3.2. Recuperado em 30 set., 2011, de http://www.irrodl. org/index.php/irrodl/article/view/375/957

Gil, A. C. (2008). Como elaborar projetos de pesquisa (4a.ed.) São Paulo: Atlas.

Jun, J. (2005) Understanding dropout of adult learners in e-learning. (Tese Doutorado em Filosofia). Universidade da Georgia. Athens, Georgia. Recuperado em 19 out. 2011, de: http://athenaeum.libs.uga.edu/bitstream handle/10724/8159/jun_jusung_200505_phd. pdf? sequence $=1$

Kemp, W. (2001). Persistence of adult learners in distance education. (Dissertação de Mestrado). Athabasca University Governing Council, Athabasca, Alberta, Canadá. Recuperado em 23 outubro, 2011, de http://auspace.athabascau ca:8080/dspace/bitstream/2149/541/1/kemp.pdf

Nassar, S. M., Ohira, M., Cislaghi, R. S., Rodrigues, A. H. Catapan (2008). Catapan, Do modelo presencial para o modelo a distância: variáveis endógenas e os riscos de evasão nos cursos de graduação. In $V$ Congresso Brasileiro de Ensino Superior a Distância - ESUD, Gramado, RS. Recuperado em 29 novembro, 2011, de http://200.169.53.89/download/CD\%20 congressos/2008/V\%20ESUD/trabs/t38620.pdf

Rossi, L. (2008). Causas da evasão em curso superior a distância do consórcio da Universidade Aberta do Brasil. (Dissertação de Mestrado). Curso em Pós-Graduação Lato Sensu em Educação a Distância, Centro de Educação a Distância, Universidade de Brasília, DF

Santos, E. M., \& Neto, J. D. O. (2009). Evasão na educação a distância: identificando causas e propondo estratégias de prevenção. Revista Paidéi@, Revista Científica de Educação a Distância, 2(2), 1-28. Recuperado em 10 janeiro, 2011, de http://revistapaideia.unimesvirtual.com.br.

Silveira, L. M. C., \& Ribeiro, V. M. B. (2004). Grupo de adesão ao tratamento: espaço de "ensinagem" para profissionais de saúde e pacientes. Interface - Comunic., Saúde, Educ. 9(16), 91-104. doi: http://dx.doi.org/10.1590/S141432832005000100008

Willis, B., \& Carmichael, K. D. (2011). The lived experience of late-stage doctoral student attrition in counselor education. The Qualitative Report, 16(1), 192-207. Recuperado em 31 de janeiro, 2012 de http://www.nova.edu/ssss/QR/QR16-1/ willis.pdf

Xenos, M., Pierrakeas, C., \& Pintelas, P. (2002). A survey on student dropout rates and dropout causes concerning the students in the Course of Informatics of the Hellenic Open University. Computers \& Education, 39(4), 361-377. doi: http://dx.doi.org/10.1016/S0360-1315(02)00072-6, 